\title{
Niil 高知工科大学
}

Ver sat i l ity of One-pot, Si ngl e- step Synt het i c Appr oach for Spher i cal Por ous ( Net al) Oxi de Nanoparti cl es Using Supercriti cal Al cohol s

\begin{tabular}{|l|l|}
\hline 著者 & $\begin{array}{l}\text { Wang Pengyu, Ueno Ki mi yoshi , Taki gawa Hi kar u, } \\
\text { Kobi r o Kazuya }\end{array}$ \\
\hline $\begin{array}{l}\text { j our nal or } \\
\text { publ i cat i on ti tl e }\end{array}$ & The Journal of Supercriti cal Fl ui ds \\
\hline vol ume & 78 \\
\hline page r ange & 124 131 \\
\hline year & 2013 \\
\hline URL & ht t p: //hdl . handl e. net /10173/1361 \\
\hline
\end{tabular}




\section{Versatility of One-pot, Single-step Synthetic Approach for Spherical}

\section{Porous (Metal) Oxide Nanoparticles Using Supercritical Alcohols}

Pengyu Wang ${ }^{*}$, Kimiyoshi Ueno, Hikaru Takigawa, Kazuya Kobiro*

School of Environmental Science and Engineering, Kochi University of Technology, 185

Miyanokuchi, Tosayamada, Kochi 782-8502, Japan

\section{Graphical abstract}

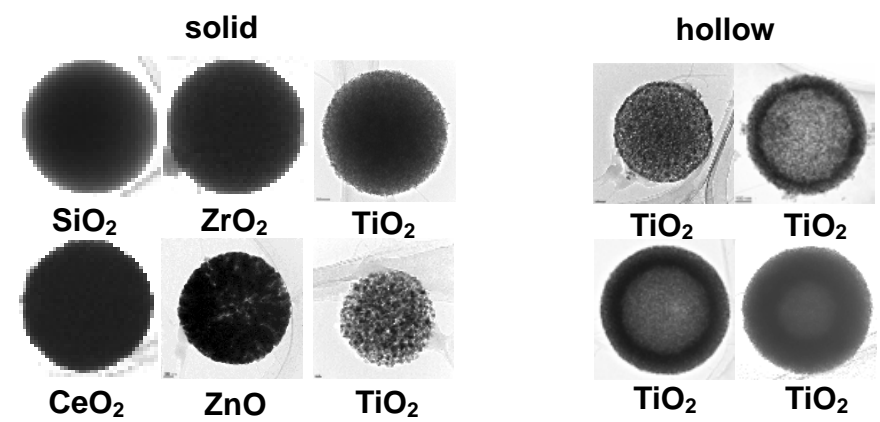

*Corresponding author. Tel.: +81 88757 2503; fax: +81 887572520 .

E-mail address: wang.pengyu@kochi-tech.ac.jp (P. Wang);

kobiro.kazuya@kochi-tech.ac.jp (K. Kobiro) 


\section{ABSTRACT}

We developed a rapid, one-pot, single-step synthetic method for preparing spherical porous (metal) oxides, titanium dioxide, silica, zirconium dioxide, cerium dioxide, and zinc oxide with large surface areas in a supercritical alcohol containing formic acid or phthalic acid as organic additive in a very short reaction time (10 min). A new type of hollow $\mathrm{TiO}_{2}$ nanoparticle was obtained by slowly heating the reaction mixtures. The shell thickness of hollow $\mathrm{TiO}_{2}$ nanoparticles was controlled by adjusting the heating rate. The method proved highly versatile for synthesizing solid and hollow spherical meso/microporous nanoparticles. The spherical mesoporous $\mathrm{TiO}_{2}$ nanoparticles photocatalytically degraded methylene blue in water under UV irradiation, and successfully transported DNA under biolistic bombardment.

Keywords: Hollow and solid spherical meso/microporous, (Metal) oxide, One-pot, Single-step, Supercritical alcohol 


\section{Introduction}

Porous materials such as zeolites [1-3], metal organic frameworks [4-6], and metal oxides [7-10] are characterized by large surface areas and controlled pore dimensions. Consequently, they have attracted substantial attention in the fields of gas absorption, separation, condensation, drug delivery, and substrate-size-controlled catalysis [1-10]. Among them, metal oxide nanoparticles, such as silica $\left(\mathrm{SiO}_{2}\right)$ [11-13], titanium dioxide $\left(\mathrm{TiO}_{2}\right)$ [14-17], cerium dioxide $\left(\mathrm{CeO}_{2}\right)$ [18-20], zirconium dioxide $\left(\mathrm{ZrO}_{2}\right)$ [21,22], and variants of these [23], are of particular relevance to catalytic chemistry, semiconductors, and drug delivery. Porous metal oxide nano- or micro-spheres with dimension-controlled morphology possess unique properties that are especially suited to practical applications. These properties include easy manipulation, effective catalyst recovery, excellent thermal stability, monodisperse nature, and exceptional light-harvesting properties [24-26]. We have designated such meso/microporous nanospheres as meso/microporously architected roundly integrated metal oxide (MARIMO) nanoparticles, because their shapes resemble those of MARIMO (Cladophora aegagropila) moss balls. Several methods exist by which to obtain these structures, including hydrothermal, sol-gel, and self-assembly methods, and combinations of these. However, these methods generally involve complex multistep 
operations and long reaction times (several hours) [1-13,14-23,27,28]. Recently, sizeand morphology-controlled inorganic-organic hybrid metal and metal oxide nanoparticles have been synthesized in supercritical fluids. Supercritical ethanol (scEtOH) yields monodisperse metal nanoparticles [29], supercritical methanol (scMeOH) [30,31] or supercritical water (SCW) [32] yields zinc oxide (ZnO) nanoparticles, while SCW alone yields $\mathrm{CeO}_{2}$ [33], $\mathrm{TiO}_{2}$ [34], and magnetite $\left(\mathrm{Fe}_{3} \mathrm{O}_{4}\right)$ [35] nanoparticles. All of these reactions proceed in a short reaction time (several seconds to several minutes) [36-41]. However, a versatile synthetic method for MARIMO nanoparticles in supercritical fluids has yet to be established.

Fig. 1

Very recently, we developed a one-pot, single-step method that synthesizes a series of spherical mesoporous $\mathrm{TiO}_{2}$ nanoparticles with large specific surface areas. The reaction mixture comprises scMeOH in the presence of a carboxylic acid, and the reaction is completed within several minutes (Fig. 1) [14]. The particle and pore sizes of the MARIMO $\mathrm{TiO}_{2}$ are controlled by changing the reaction temperature (Fig. 1a and b). In addition, by merely changing the carboxylic acid, both solid and hollow MARIMO $\mathrm{TiO}_{2}$ are produced (Fig. 1c). In this paper, we show that the synthetic approach can yield a variety of other (metal) oxide nanospheres such as $\mathrm{SiO}_{2}, \mathrm{CeO}_{2}, \mathrm{ZrO}_{2}$, and $\mathrm{ZnO}$. The 
method can also synthesize a new type of hollow MARIMO $\mathrm{TiO}_{2}$ nanosphere with thickness-controllable shell. 


\section{Materials and methods}

\subsection{General information}

Ethanol, methanol, phthalic acid, formic acid, acetic acid, tetraethyl orthosilicate, zirconium oxynitrate dihydrate, cerium (III) nitrate hexahydrate, titanium tetraisopropoxide, zinc acetate dihydrate, and methylene blue were purchased from Wako Pure Chemical Industries Co. Ltd. They were used as received without further purification.

\subsection{Characterization}

X-ray diffraction (XRD) patterns were obtained using Rigaku SmartLab with graphite-monochromatized $\mathrm{Cu} K \alpha$ radiation. Transmission electron microscope (TEM) and high-resolution transmission electron microscopy (HRTEM) images were taken using JEOL JEM-2100F. Field emission scanning electron microscope (FESEM) images were taken on JEOL JSM7300F. Fourier transform infrared (FTIR) spectra were obtained using JASCO FT/IR-4200 (type A). Dynamic light scattering (DLS) analyses were performed using a Photal FPAR-1000 Fiber-Optics Particle Analyzer. Nitrogen adsorption-desorption isotherm spectra were obtained using BEL Japan INC Belsorp II and Brunauer-Emmett-Teller (BET) specific surface areas were obtained using BET 
Shimadzu FlowSorb II 2300. Ultraviolet visible absorption (UV-vis) spectra of the nanoparticles were obtained using JASCO V-670.

\subsection{Preparation of mesoporous nanoparticles}

A metal salt (2 mmol) was added to a solution of carboxylic acid in $20 \mathrm{~mL}$ of methanol or ethanol $\left(0.5 \mathrm{~mol} \mathrm{~L}^{-1}\right)$, with vigorous stirring.

Synthesis of spherical meso/microporous (metal) oxide nanoparticles in supercritical alcohols by rapid heating: The $\mathrm{MeOH}$ or EtOH solution $(3.5 \mathrm{~mL})$ was transferred into an SUS 316 batch-type reactor (10 mL volume). The reactor was sealed with a screw cap equipped with a thermocouple for measuring the inner reactor temperature. The reactor was then placed in a molten salt bath maintained at an appropriate temperature, and heated for an appropriate time. The reaction was quenched by placing the reactor into an ice-water bath. The screw cap was opened after the reactor had cooled completely. The crude product was sonicated in $\mathrm{MeOH}$ or EtOH (30 min) and centrifuged (6600 rpm, $10{ }^{\circ} \mathrm{C}$, and $30 \mathrm{~min}$ ). The upper layer was decanted. This procedure was undertaken three times. The obtained powdery product was vacuum-dried at $30^{\circ} \mathrm{C}$ for $24 \mathrm{~h}$. 
Synthesis of spherical mesoporous metal oxide nanoparticles in supercritical alcohols by slow heating: The reactor was heated from $30{ }^{\circ} \mathrm{C}$ to an appropriate temperature at an appropriate heating speed in a gas chromatography oven. After reaction, the reactor was cooled at an appropriate rate or placed into an ice-water bath.

\subsection{Photocatalytic degradation of methylene blue}

MARIMO $\mathrm{TiO}_{2}$ nanoparticles were calcined at $500{ }^{\circ} \mathrm{C}$ for $60 \mathrm{~min}$ to remove surface organic materials. The MARIMO $\mathrm{TiO}_{2}$ nanoparticles $(5 \mathrm{mg}$ ) were dispersed in $5 \mathrm{~mL}$ of methylene blue water solution $\left(1.0 \times 10^{-5} \mathrm{~mol} \mathrm{~L}^{-1}\right)$. The photocatalytic degradation was performed in a quartz cell irradiated by a $300 \mathrm{~W}$ xenon light source (Asahi spectra, MAX-301). Light of wavelength longer than $370 \mathrm{~nm}$ was removed by an optical filter. Following irradiation for an appropriate time, the catalyst was removed by a membrane filter (Millipore, MILLEX-HV $0.45 \mu \mathrm{m}$ Filter Unit) and the absorption spectra of the filtrate were measured on a UV-vis spectrophotometer (JASCO V-560). 


\section{Results and discussion}

Microporous $\mathrm{SiO}_{2}$ nanospheres were obtained by reacting tetraethoxysilane in scEtOH $\left(0.28 \mathrm{~g} \mathrm{~mL}^{-1}\right)$ at $400{ }^{\circ} \mathrm{C}$ for $10 \mathrm{~min}$ in the presence of phthalic acid. This reaction yielded a white powder; however, a similar reaction using scMeOH yielded very few particles. From field emission scanning electron microscopy (FESEM) and transmission electron microscopy (TEM) images, the particles obtained in scEtOH are seen to possess the characteristic MARIMO morphology (Fig. 2a, 2b, and S1). Broad peaks observed in the powder XRD pattern of the particles clearly indicate their amorphous $\mathrm{SiO}_{2}$ nature (Fig. 3a)[42]. The average size of the MARIMO $\mathrm{SiO}_{2}$ particles obtained at $400{ }^{\circ} \mathrm{C}$ is $1316 \pm 305 \mathrm{~nm}$ (dynamic light scattering (DLS) measurements; Fig. S2) and the particle size distribution is very narrow. The Brunauer-Emmett-Teller (BET) specific surface area density of the MARIMO $\mathrm{SiO}_{2}$ nanoparticles is $715 \mathrm{~m}^{2} \mathrm{~g}^{-1}$, larger than some of the reported and commercially available MARIMO $\mathrm{SiO}_{2}$ microspheres [11-13]. The nitrogen adsorption-desorption isotherm of the MARIMO $\mathrm{SiO}_{2}$ microparticles is of type $\mathrm{I}$, indicating that the synthesized MARIMO $\mathrm{SiO}_{2}$ microparticles are microporous (Fig. 4a and b). To examine whether surface organic residues exist on the MARIMO $\mathrm{SiO}_{2}$ microparticles, Fourier transform infrared (FTIR) reflection spectra were acquired (Fig. S3). A broad absorption appeared at 3700-3000 
$\mathrm{cm}^{-1}$, consistent with hydrogen-bonded $\mathrm{O}-\mathrm{H}$ stretching on the surface of the $\mathrm{SiO}_{2}$ microparticles and/or absorbed $\mathrm{H}_{2} \mathrm{O}$. The absorptions at 2975 and $2894 \mathrm{~cm}^{-1}$ are attributable to $\mathrm{C}-\mathrm{H}$ stretching vibrations of the organic compounds on the $\mathrm{SiO}_{2}$ surface. The absorptions at $1650-1550$ and $1409 \mathrm{~cm}^{-1}$ correspond to absorptions of the carboxylate $\left(\mathrm{COO}^{-}\right)$group, indicating that phthalic acid is attached to the surface of the MARIMO $\mathrm{SiO}_{2}$ microparticles. These results indicated that the carboxylic acid could interconnect the primary particles of MARIMO nanoparticles and/or simply cover the surface of the primary particles. The broad, intense bands appearing at 1087 and 800 $\mathrm{cm}^{-1}$ correspond to the symmetric stretching vibration of $\mathrm{Si}-\mathrm{O}-\mathrm{Si}$, while the sharp peak at $970 \mathrm{~cm}^{-1}$ corresponds to $\mathrm{Si}-\mathrm{OH}[43,44]$.

Fig. 2

Fig. 3

Fig. 4

The one-pot, one-step supercritical alcohol method was then applied to the synthesis of MARIMO $\mathrm{ZrO}_{2}$ and $\mathrm{CeO}_{2}$ nanoparticles. Each of these particles was readily obtained by exposing the corresponding metal salt $\left(\mathrm{ZrO}\left(\mathrm{NO}_{3}\right)_{2} \cdot 2 \mathrm{H}_{2} \mathrm{O}\right.$ or $\mathrm{Ce}\left(\mathrm{NO}_{3}\right)_{3} \cdot 6 \mathrm{H}_{2} \mathrm{O}$, respectively) to formic acid in $\mathrm{scMeOH}\left(0.28 \mathrm{~g} \mathrm{~mL}^{-1}\right)$. The reaction proceeded at $300{ }^{\circ} \mathrm{C}$ for 10 min. TEM images of $\mathrm{ZrO}_{2}$ (Fig. 2c and d) and $\mathrm{CeO}_{2}$ (Fig. 2e and f) 
nanoparticles indicate that all of the obtained nanoparticles possess the MARIMO morphology. XRD diffraction patterns revealed the crystal structures of the nanoparticles as tetragonal for $\mathrm{ZrO}_{2}$ and cubic for $\mathrm{CeO}_{2}$ (Fig. 3b and c). From dynamic light scattering (DLS) measurements, the average diameters of the nanoparticles were determined as $485 \pm 274 \mathrm{~nm}$ (Fig. S9a) and $1190 \pm 854 \mathrm{~nm}$ (Fig. S15a) for $\mathrm{ZrO}_{2}$ and $\mathrm{CeO}_{2}$, respectively. The respective BET specific surface area densities are $228 \mathrm{~m}^{2} \mathrm{~g}^{-1}$ and $34 \mathrm{~m}^{2} \mathrm{~g}^{-1}$. The nitrogen adsorption-desorption isotherms of the MARIMO $\mathrm{ZrO}_{2}$ and $\mathrm{CeO}_{2}$ nanoparticles were of types I and IV, respectively, indicating that the MARIMO $\mathrm{ZrO}_{2}$ nanoparticles are microporous (Fig. 4c and d) and the MARIMO $\mathrm{CeO}_{2}$ nanoparticles are mesoporous (Fig. 4e and f). A higher reaction temperature $\left(400{ }^{\circ} \mathrm{C}\right)$ yielded slightly smaller MARIMO nanoparticles of $\mathrm{ZrO}_{2}(428 \pm 236 \mathrm{~nm}$, Fig. S9b) and $\mathrm{CeO}_{2}\left(653 \pm 326 \mathrm{~nm}\right.$, Fig. S15b) with reduced specific surface area (154 and $31 \mathrm{~m}^{2} \mathrm{~g}^{-1}$, respectively). A similar procedure easily afforded divalent metal oxide, MARIMO ZnO, nanoparticles (Fig. S16-S19). These results confirm the successful fabrication of MARIMO $\mathrm{TiO}_{2}$ [14], $\mathrm{SiO}_{2}, \mathrm{ZrO}_{2}, \mathrm{CeO}_{2}$, and $\mathrm{ZnO}$. Thus, the simple one-pot, one-step reactions of (metal) salts in the presence of carboxylic acids in supercritical alcohols is available means of obtaining spherical porous nanoparticles within a few minutes. 
Rapidly heating a reaction mixture comprising $\mathrm{Ti}\left(\mathrm{O}^{i} \mathrm{Pr}\right)_{4}$, formic acid, and $\mathrm{MeOH}$ to $400{ }^{\circ} \mathrm{C}$ (within $30 \mathrm{~s}$ ) yields well-formed hollow $\mathrm{TiO}_{2}$ nanospheres with a very thin shell as reported before (Fig. 1c) [14]. In the current study, we synthesized another type of hollow MARIMO $\mathrm{TiO}_{2}$ nanoparticle, whose shell thickness was controlled by tuning the heating rate of the reaction. Slowly heating a reaction mixture of $\mathrm{Ti}\left(\mathrm{O}^{i} \mathrm{Pr}\right)_{4}$, phthalic acid, and $\mathrm{MeOH}$ from room temperature to 300 or $400{ }^{\circ} \mathrm{C}$ (ca. $5.4{ }^{\circ} \mathrm{C} / \mathrm{min}$ ) produced well-formed hollow MARIMO anatase $\mathrm{TiO}_{2}$ nanoparticles with a thick shell (thickness 140 and 105 nm [45], respectively; Fig. 5a-d and 6a; 5e-h and 6b).The hollow structures of the nanoparticles were directly confirmed by FESEM images of broken particles (Fig. $5 b$ and 5f). The lower temperature $\left(300{ }^{\circ} \mathrm{C}\right)$ resulted in small-sized primary nanoparticles (Fig. 5d), while the higher temperature $\left(400{ }^{\circ} \mathrm{C}\right)$ yielded larger ones (Fig. 5h), consistent with the results for solid MARIMO $\mathrm{TiO}_{2}$ nanospheres [14]. Moreover, lowering the reaction temperature to $200{ }^{\circ} \mathrm{C}$ yielded hollow MARIMO amorphous $\mathrm{TiO}_{2}$ (Fig. S30 and S31). The specific surface area of the hollow MARIMO $\mathrm{TiO}_{2}$ nanoparticles obtained at $300{ }^{\circ} \mathrm{C}$ is $178 \mathrm{~m}^{2} \mathrm{~g}^{-1}$, and their structures contain mesopores (Fig. S25). In addition, slower heating (ca. $2{ }^{\circ} \mathrm{C} / \mathrm{min}$ ) provided hollow MARIMO anatase $\mathrm{TiO}_{2}$ nanoparticles with a thicker shell (281 nm [45]; Fig. 5i-l and 6c). More rapid heating (ca. $10^{\circ} \mathrm{C} / \mathrm{min}$ ) reduced the shell thickness to $120 \mathrm{~nm}$ [45] (Fig. 5m-p, 6d). 
Thus, the hollow MARIMO morphology depends critically on heating rate; however, slow cooling from higher temperatures exerted no effect on MARIMO morphology (where slow cooling denotes ca. $5.4{ }^{\circ} \mathrm{C} / \mathrm{min}$ from $300{ }^{\circ} \mathrm{C}$ (Fig. S23 and S24) and ca. $5.4^{\circ} \mathrm{C} / \mathrm{min}$ from $400{ }^{\circ} \mathrm{C}$ (Fig. S27 and 28)). MARIMO structure was also independent of reaction time $(10,30$, and $60 \mathrm{~min})$ at $300{ }^{\circ} \mathrm{C}$ and $0.28 \mathrm{~g} \mathrm{~mL}^{-1} \mathrm{MeOH}$ density (Fig. 1a, S20 and S21). Hollow mesoporous $\mathrm{TiO}_{2}$ nanoparticles with controllable shell thickness have recently been synthesized using a $\mathrm{SiO}_{2}$ microsphere template [15]. While this approach is interesting and novel, our approach is considerably simpler, since ours controls shell thickness and pore size of hollow $\mathrm{TiO}_{2}$ nanoparticles by merely changing heating rate in a one-pot single-step reaction.

Fig. 5

Fig. 6

The formation mechanisms of MARIMO nanoparticles were investigated by modifying the reaction conditions [46]. First, $\mathrm{MeOH}$ was replaced with 2-propanol as solvent in the reaction of $\mathrm{Ti}\left(\mathrm{O}^{i} \mathrm{Pr}\right)_{4}$ with phthalic acid or $\mathrm{HCOOH}$ under similar reaction conditions. However, dispersed single $\mathrm{TiO}_{2}$ crystals rather than $\mathrm{MARIMO} \mathrm{TiO}_{2}$ were obtained in both reactions (Fig. S34). The presence of carboxylic acid is also important. When the reaction was executed in scMeOH without carboxylic acid, aggregated single 
crystals again resulted (Fig. S36), whereas MARIMO nanoparticles always formed in the presence of acid (Fig. S37 and S38). Moreover, pore sizes of the MARIMO $\mathrm{TiO}_{2}$ nanoparticles increased at higher concentrations of carboxylic acid (Fig. S37 and S38). Thus, the combination of scMeOH and carboxylic acid is crucial for the formation of the MARIMO nanoparticles.

Based on these results, we have proposed a carboxyl-group-assisted process for the formation of solid MARIMO nanoparticles (Scheme 1, rapid heating) [14]; substitution of sterically bulky isopropoxy groups by less-bulky methoxy groups forms primitive titanium alkoxide oligomers by transesterification at high temperature in the presence of carboxylic acid in methanol [47]. Under these conditions, some of the primitive oligomers are interconnected via surface interactions with carboxyl groups. As the reaction mixture is heated further, esterification of acids with methanol proceeds easily with water formation. The titanium alkoxide oligomers bearing carboxylic acids react with the water to form $\mathrm{TiO}_{2}$ crystals [28]. Parallel decomposition of the carboxylic acid evolves gaseous products such as $\mathrm{CO}_{2}$ and hydrocarbons. These processes occur rapidly under rapid heating (within $30 \mathrm{sec}$ ), with consequent expansion of the nanospheres to ultimately yield either solid or thin-shelled hollow MARIMO nanoparticles (Scheme 1, rapid heating). On the other hand, hollow thick-shelled MARIMO nanoparticles are 
formed under slow heating rate by the Ostwald ripening effect (Scheme 1, slow heating) $[48,49]$. Since low reaction temperature $\left(200{ }^{\circ} \mathrm{C}\right)$ resulted in amorphous $\mathrm{MARIMO} \mathrm{TiO}_{2}$ and slower heating rate increased the shell thickness of the nanospheres, we infer that amorphous $\mathrm{TiO}_{2}$ generated first at low temperature becomes crystalline with rising temperature concomitant with the Ostwald ripening effect. Poorly-formed crystals are lost, resulting in larger and more complete single crystals with thick-shelled hollow MARIMO morphology. Slower heating also enhances the Ostwald ripening effect that favors the hollow MARIMO morphology with larger primary particles, as well as thicker shell wall.

\section{Scheme 1.}

To assess the efficacy of MARIMO $\mathrm{TiO}_{2}$ as a photocatalytic material, we tested its ability to degrade methylene blue in water. The MARIMO $\mathrm{TiO}_{2}$ nanoparticles used for this purpose were obtained in the presence of phthalic acid in scMeOH $\left(0.28 \mathrm{~g} \mathrm{~mL}^{-1}\right)$ at $300^{\circ} \mathrm{C}$ (reaction time $10 \mathrm{~min}$; Fig. 1a). The UV-vis spectrum of the particles is shown in Fig. S39. The MARIMO $\mathrm{TiO}_{2}$ nanoparticles absorbed light at wavelengths shorter than $400 \mathrm{~nm}$. The nanoparticles were dispersed throughout the methylene blue water solution. Fig. 7 illustrates the degradation of methylene blue in the presence of $\mathrm{MARIMO} \mathrm{TiO}_{2}$ nanoparticles under irradiation by $370 \mathrm{~nm}$ UV light. The solution became colorless after 
10 min, indicating that the MARIMO $\mathrm{TiO}_{2}$ nanoparticles can properly degrade methylene blue under UV irradiation (370 nm). Although the specific surface area of MARIMO $\mathrm{TiO}_{2}$ is larger than that of commercially available P25, the reaction rate $\left(k_{f}=\right.$ $2.9 \times 10^{-1} \mathrm{~min}^{-1}$ ) of photodegradation by MARIMO $\mathrm{TiO}_{2}$ as a catalyst was smaller as compare to that by commercially available P25 $\left(k_{f}=1.52 \mathrm{~min}^{-1}\right.$, Fig. S40). It can be due to inside of MARIMO $\mathrm{TiO}_{2}$ is not available effectively, since light could not penetrate deeply inside of MARIMO $\mathrm{TiO}_{2}$ and/or methylene blue did not diffuse inside. Only surface of MARIMO, namely, can be used efficiently in this reaction.

\section{Fig. 7}

Moreover, the MARIMO $\mathrm{TiO}_{2}$ nanoparticles were successfully applied as a new material for transporting DNA under biolistic bombardment [50]. The current gold or tungsten nanoparticles used for biolistic bombardment are classified as nano-aggregates, with average aggregation sizes of several hundred nanometers. Our MARIMO $\mathrm{TiO}_{2}$ nanoparticles possess size-controlled complete spherical structure with numerous mesopores which can readily admit plasmids. The MARIMO $\mathrm{TiO}_{2}$ nanoparticles shown in Fig. 1a were used for this purpose. The MARIMO $\mathrm{TiO}_{2}$ nanoparticles were mixed with supercoiled pHyg3 plasmid carrying the hygromycin resistance gene aphVII. The particles were shot into Chlamydomonas reinhardtii cells by high pressure He gas (7.6 
MPa). After two weeks, colonies appeared on hygromycin-infused agar plates, confirming that the novel MARIMO $\mathrm{TiO}_{2}$ nanoparticles had successfully transported DNA under biolistic bombardment (Fig. 8). Thus, the $\mathrm{MARIMO} \mathrm{TiO}_{2}$ nanoparticles delivered the DNA despite their reduced density and can replace the heavy, expensive gold and tungsten nanoparticles currently used in DNA transport.

Fig. 8 


\section{Conclusions}

Meso/microporously architected roundly integrated (metal) oxide (MARIMO) $\mathrm{TiO}_{2}$, $\mathrm{SiO}_{2}, \mathrm{ZrO}_{2}, \mathrm{CeO}_{2}$, and $\mathrm{ZnO}$ nanoparticles with large surface areas were successfully synthesized by a simple one-pot, one-step synthetic approach in the presence of carboxylic acids (phthalic acid and formic acid) as organic additives in supercritical alcohols. The reaction proceeds over a short time scale. A new type of hollow $\mathrm{TiO}_{2}$ nanoparticle resulted from slow heating of the reaction mixtures. The thickness of the shell can be controlled by adjusting the heating rate. The one-pot, one-step synthetic method was extremely versatile, yielding a series of solid and hollow MARIMO nanoparticles. The synthesized MARIMO $\mathrm{TiO}_{2}$ nanoparticles were successfully applied to two practical situations; UV-assisted photocatalytic degradation of methylene blue in water, and DNA transport under biolistic bombardment. 


\section{Acknowledgements}

The authors gratefully acknowledge Mr. Masao Yamashita and Dr. Tsutomu Nakanishi of Kagawa Industry Support Foundation for the synthesis of hollow MARIMO $\mathrm{TiO}_{2}$ nanoparticles. The authors extend their sincere thanks to Prof. Tomoya Konishi of Anan National College of Technology for FTIR analyses. The authors are sincerely grateful to Prof. Hiromichi Aono of Ehime University for the BET and nitrogen adsorption-desorption isotherm spectra. The authors thank Prof. Nagatoshi Nishiwaki and Dr. Noriko Nitta of Kochi University of Technology for their fruitful discussions. The authors also thank Mr. Tetsuo Nagayama and Mr. Masato Sato of social cooperation division of Kochi University of Technology for their support. 


\section{References}

[1] H. Chen, J. Wydra, H. Zhang, P.-S. Lee, Z. Wang, W. Fan, M. Tsapatsis, Hydrothermal synthesis of zeolites with three-dimensionally ordered mesoporous-imprinted structure, J. American Chemical Society 133 (2011) 12390-12393.

[2] Q. Meng, D.C. Doetschman, A.K. Rizos, M.-H. Lee, J.T. Schulte, A. Spyros, C.W. Kanyi, Adsorption of organophosphates into microporous and mesoporous $\mathrm{NaX}$ zeolites and subsequent chemistry, Environmental Science Technology, 45 (2011) 3000-3005.

[3] J. Zhao, J. Zhou, Y. Chen, Q. He, M. Ruan, L. Guo, J. Shi, H. Chen, Fabrication of mesoporous zeolite microspheres by a one-pot dual-functional templating approach, J. Materials Chemistry, 19 (2009) 7614-7616.

[4] S. Xiang, Y. He, Z. Zhang, H. Wu, W. Zhou, R. Krishna, B. Chen, Microporous metal-organic framework with potential for carbon dioxide capture at ambient conditions, Nature Communications, DOI: 10.1038/ncomms1956.

[5] N. Stock, S. Biswas, Synthesis of Metal-Organic Frameworks (MOFs): Routes to various MOF topologies, morphologies, and composites, Chemical Reviews 112 (2012) 933-969. 
[6] M. Yoon, R. Srirambalaji, K. Kim, Homochiral metalorganic frameworks for asymmetric heterogeneous catalysis, Chemical Reviews 112 (2012) 1196-1231.

[7] X. Sun, Y. Shi, P. Zhang, C. Zheng, X. Zheng, F. Zhang, Y. Zhang, N. Guan, D. Zhao, G.D. Stucky, Container effect in nanocasting synthesis of mesoporous metal oxides, J. American Chemical Society 133 (2011) 14542-14545.

[8] W. Cai, J. Yu, C. Anand, A. Vinu, M. Jaroniec, Facile synthesis of ordered mesoporous alumina and alumina-supported metal oxides with tailored adsorption and framework properties, Chemistry of Materials 23 (2011) 1147-1157.

[9] N.C. Strandwitz, G.D. Stucky, Hollow Microporous cerium oxide spheres templated by colloidal silica, Chemistry of Materials 21 (2009) 4577-4582.

[10] X. Liang, M. Yu, J. Li, Y.-B. Jiang, A.W. Weimer, Ultra-thin microporous-mesoporous metal oxide films prepared by molecular layer deposition (MLD), Chemical Communications (2009) 7140-7142.

[11] F. Tang, L. Li, D. Chen, Mesoporous silica nanoparticles: synthesis, biocompatibility and drug delivery, Advanced Materials 24 (2012) 1504-1534.

[12] Y.L. Choi, J.H. Lee, J. Jaworski, J.H. Jung, Mesoporous silica nanoparticles functionalized with a thymidine derivative for controlled release, J. Materials Chemistry 22 (2012) 9455-9457. 
[13] P. Yang, S. Gai, J. Lin, Functionalized mesoporous silica materials for controlled drug delivery, Chemical Society Reviews, 41 (2012) 3679-3698.

[14] P. Wang, K. Kobiro, Ultimately simple one-pot synthesis of spherical mesoporous $\mathrm{TiO}_{2}$ nanoparticles in supercritical methanol, Chemistry Letters 41 (2012) 264-266.

[15] J.B. Joo, Q. Zhang, I. Lee, M. Dahl, F. Zaera, Y. Yin, Mesoporous anatase titania hollow nanostructures though silica-protected calcination, Advanced Functional Materials 22 (2012) 166-174.

[16] M.P. Hong, J.Y. Kim, K. Vemula, H.S. Kim, K.B. Yoon, Synthesis of monodisperse mesoporous $\mathrm{TiO}_{2}$ spheres with tunable sizes between 0.6 and $3.1 \mathrm{~lm}$ and effects of reaction temperature, Ti source purity, and type of alkylamine on size and monodispersity, Chemical Communications 48 (2012) 4250-4252.

[17] Z. Sun, J.H. Kim, Y. Zhao, F. Bijarbooneh, V. Malgras, Y. Lee, Y.-M. Kang, S.X. Dou, Rational design of $3 \mathrm{D}$ dendritic $\mathrm{TiO}_{2}$ nanostructures with favorable architectures, J. American Chemical Society 133 (2011) 19314-19317.

[18] J. Wei, Z. Yang, Y. Yang, Fabrication of three dimensional $\mathrm{CeO}_{2}$ hierarchical structures: precursor template synthesis, formation mechanism and properties, CrystEngComm 13 (2011) 2418-2424. 
[19] Z. Yang, J. Wei, H. Yang, L. Liu, H. Liang, Y. Yang, Mesoporous $\mathrm{CeO}_{2}$ hollow spheres prepared by Ostwald ripening and their environmental applications, European J. Inorganic Chemistry (2010) 3354-3359.

[20] T. Brezesinski, J. Wang, R. Senter, K. Brezesinski, B. Dunn, S.H. Tolber, On the correlation between mechanical flexibility, nanoscale structure, and charge storage in periodic mesoporous $\mathrm{CeO}_{2}$ thin films, ACS Nano. 4 (2010) 967-977.

[21] Y. Chen, S.K. Lunsford, Y. Song, H. Ju, P. Falaras, V. Li-kodimos, A.G. Kontos, D.D. Dionysiou, Synthesis, characterization and electrochemical properties of mesoporous zirconia nanomaterials prepared by self-assembling sol-gel method with Tween 20 as a template, Chemical Engineering J. 170 (2011) 518-524.

[22] A. Mondal, A. Zachariah, P. Nayak, B.B. Nayak, Synthesis and room temperature photoluminescence of mesoporous zirconia with a tetragonal nanocrystalline framework, J. American Ceramic Society 93 (2010) 387-392.

[23] X. Lai, J. Li, B. A. Korgel, Z. Dong, Z. Li, F. Su, J. Du, D. Wang, General synthesis and gas-sensing properties of multiple-shell metal oxide hollow microspheres, Angewandte Chemmie International Edition 50 (2011) 2738-2741. 
[24] S. Liu, J. Yu, M. Jaroniec, Tunable photocatalytic selectivity of hollow $\mathrm{TiO}_{2}$ microspheres composed of anatase polyhedra with exposed $\{001\}$ facets, J. American Chemical Society 132 (2010) 11914-11916.

[25] X. Hu, G. Li, J.C. Yu, Design, fabrication, and modification of nanostructured semiconductor materials for environmental and energy applications, Langmuir 26 (2009) 3031-3039.

[26] J.H. Pan, X. Zhang, A.J. Du, D.D. Sun, J.O. Leckie, Self-etching reconstruction of hierarchically mesoporous $\mathrm{F}_{-}-\mathrm{TiO}_{2}$ hollow microspherical photocatalyst for concurrent membrane water purifications, J. American Chemical Society 130 (2008) 11256-11257.

[27] A.A. Ismail, D.W. Bahnemann, Mesoporous titania photocatalysts: preparation, characterization and reaction mechanisms, J. Materials Chemistry 21 (2011) 11686-11707.

[28] X. Chen, S.S. Mao, Titanium dioxide nanomaterials: synthesis, properties, modifications, and applications, Chemical Reviews 107 (2007) 2891-2959.

[29] S.K. Pahari, T. Adschiri, A.B. Panda, Synthesis of monodispersed nanocrystalline materials in supercritical ethanol: a generalized approach, J. Materials Chemistry 21 (2011) 10377-10383. 
[30] A.A. Vostrikov, O.N. Fedyaeva, A.V. Shishkin, M.Ya. Sokol, ZnO nanoparticles formation by reactions of bulk $\mathrm{Zn}$ with $\mathrm{H}_{2} \mathrm{O}$ and $\mathrm{CO}_{2}$ at sub- and supercritical conditions: I. Mechanism and kinetics of reactions, J. Supercritical Fluids 48 (2009) 154-160.

[31] A.A. Vostrikov, O.N. Fedyaeva, A.V. Shishkin, M.Ya. Sokol, ZnO nanoparticles formation by reactions of bulk $\mathrm{Zn}$ with $\mathrm{H}_{2} \mathrm{O}$ and $\mathrm{CO}_{2}$ at sub- and supercritical conditions: II. Morphology and properties of nanoparticles, J. Supercritical Fluids 48 (2009) 161-166.

[32] B. Veriansyah, J.-D. Kim, B.K. Min, Y.H. Shin, Y.-W. Lee, J. Kim, Continuous synthesis of surface-modified zinc oxide nanoparticles in supercritical methanol, J. supercritical Fluids 52 (2010) 76-83.

[33] J. Zhang, S. Ohara, M. Umetsu, T. Naka, Y. Hatakeyama, T. Adschiri, Colloidal ceria nanocrystals: a tailor-made crystal morphology in supercritical water, Advanced Materials 19 (2007) 203-206.

[34] T. Arita, H. Hitaka, K. Minami, T. Naka, T. Adschiri, Synthesis and characterization of surface-modified FePt nanocrystals by supercritical hydrothermal method, Chemistry Letters 40 (2011) 588-590. 
[35] T. Togashi, T. Naka, S. Asahina, K. Sato, S. Takami, T. Adschiri, Surfactant-assisted one-pot synthesis of superparamagnetic magnetite nanoparticle clusters with tunable cluster size and magnetic field sensitivity, Dalton Transactions 40 (2011) 1073-1078.

[36] T. Adschiri, Y.-W. Lee, M. Goto, S. Takami, Green materials synthesis with supercritical water, Green Chemistry 13 (2011) 1380-1390.

[37] F. Cansell, C. Aymonier, Design of functional nanostructured materials using supercritical fluids, J. Supercritical Fluids 47 (2009) 508-516.

[38] K. Byrappa, S. Ohara, T. Adschiri, Nanoparticles synthesis using supercritical fluid technology - towards biomedical applications, Advanced Drug Delivery Reviews 60 (2008) 299-327.

[39] T. Adschiri, Supercritical hydrothermal synthesis of organic-inorganic hybrid nanoparticles, Chemistry Letters 36 (2007) 1188-1193.

[40] E. Reverchon, R. Adami, Nanomaterials and supercritical fluids, J. Supercritical Fluids 37 (2006) 1-22.

[41] C. Aymonier, A. Loppinet-Serani, H. Reverón, Y. Garrabos, F. Cansell, Review of supercritical fluids in inorganic materials science, J. Supercritical Fluids 38 (2006) $242-251$. 
[42] J.R. Martínez, S. Palomares-Sánchez, G. Ortega-Zarzosa, F. Ruiz, Y. Chumakov, Rietveld refinement of amorphous $\mathrm{SiO}_{2}$ prepared via sol-gel method, Materials Letters 60 (2006) 3526-3529.

[43] R. Göbel, A. Friedrich, A. Taubert, Tuning the phase behavior of ionic liquids in organically functionalized silica ionogels, Dalton Transactions 39 (2010) 603-611.

[44] Y.S. Chaudhary, J. Ghatak, U.M. Bhatta, D. Khushalani, One-step method for the self-assembly of metal nanoparticles onto facetted hollow silica tubes, J. Materials Chemistry 16 (2006) 3619-3623.

[45] Shell thickness is the average thickness calculated from 50 MARIMO $\mathrm{TiO}_{2}$ nanoparticles from the TEM images.

[46] Details are shown in electronic supplementary data.

[47] D.A. Wright, D.A. Williams, The crystal and molecular structure of titanium tetramethoxide, Acta Crystallographica - Section B: Structural Crystallography \& Crystal Chemistry 24 (1968) 1107-1714.

[48] J. Hu, M. Chen, X. Fang, L. Wu, Fabrication and application of inorganic hollow spheres, Chemical Society Reviews 40 (2011) 5472-5491.

[49] L. Ratke, P.W. Voorhees, Growth and Coarsening: Ostwald Ripening in Material Processing. Springer, 2002, pp. 117-118. 
[50] The results will be published elsewhere shortly. 